\title{
Surface stabilization of formamidinium perovskite solar cell using quaternary ammonium salt
}

Sungwon Songł, Seok Joo Yang†, Jinhyeok Choi, Se Gyo Han, Kwanghee Park, Hansol Lee, Jiwoo Min, Sunmin Ryu and Kilwon Cho*

S. Song, S. J. Yang, J. Choi, S. G. Han, J. Min, H. Lee and Prof. K. Cho

Department of Chemical Engineering, Pohang University of Science and Technology, Pohang, 37673, Korea

E-mail: kwcho@postech.ac.kr

K. Park and Prof. S. Ryu

Department of Chemistry, Pohang University of Science and Technology, Pohang, 37673, Korea 


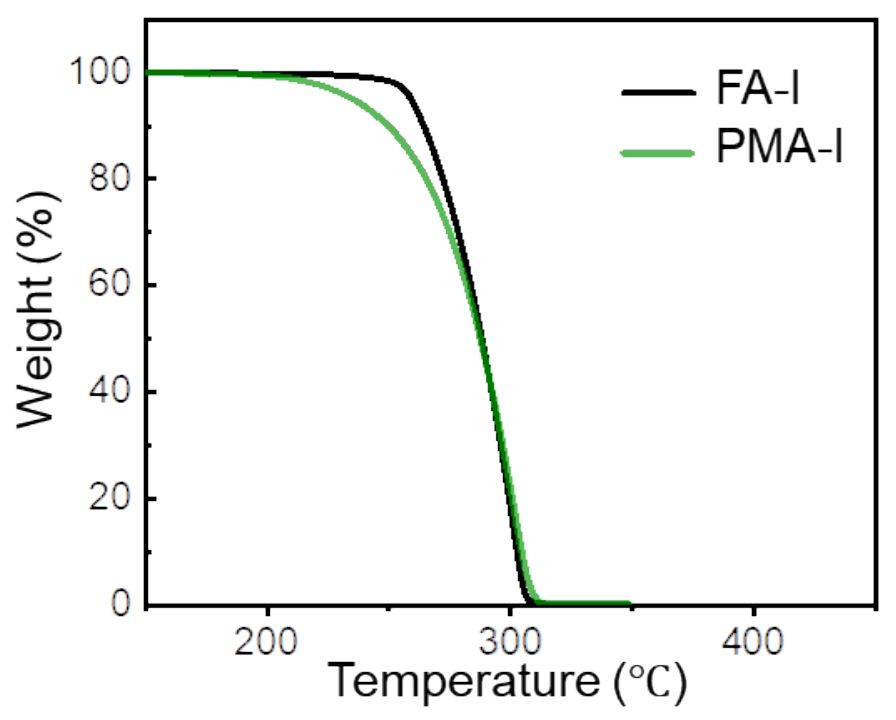

Figure S1. TGA thermograms of FA-I and PMA-I. The decomposition onset temperature of FA-I is $271.4{ }^{\circ} \mathrm{C}$ which is higher than that of PMA-I. The resonance structure of FA ion makes it less acidic than PMA ion. 


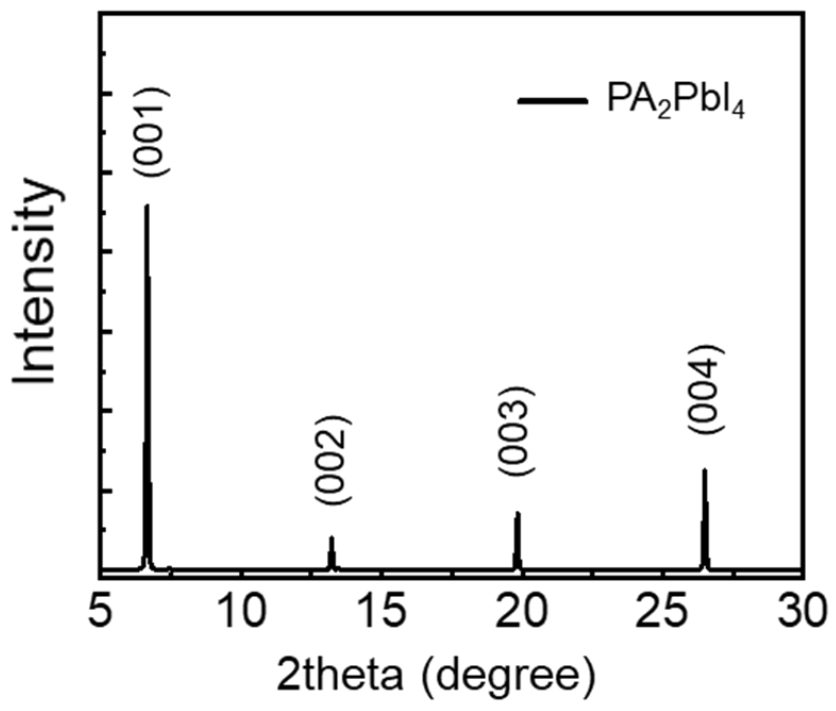

Figure S2. XRD pattern of of $\mathrm{PA}_{2} \mathrm{PbI}_{4}$ heated at $T=60^{\circ} \mathrm{C}$ for $30 \mathrm{sec}$. 
a

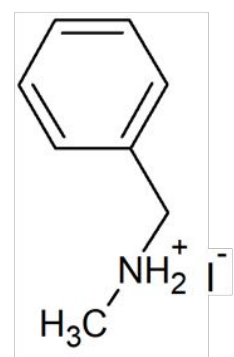

MPMA-I

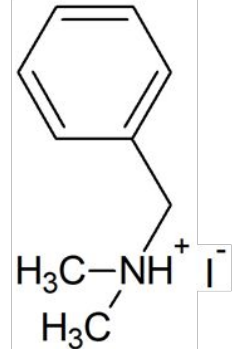

DMPMA-I b

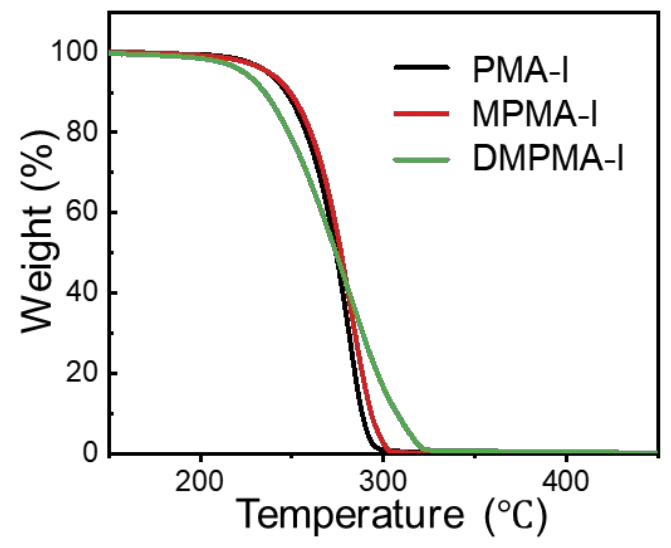

Figure S3. (a) Molecule structure of MPMA-I and DMPMA-I. (b) TGA heating curves of passivation molecules. 

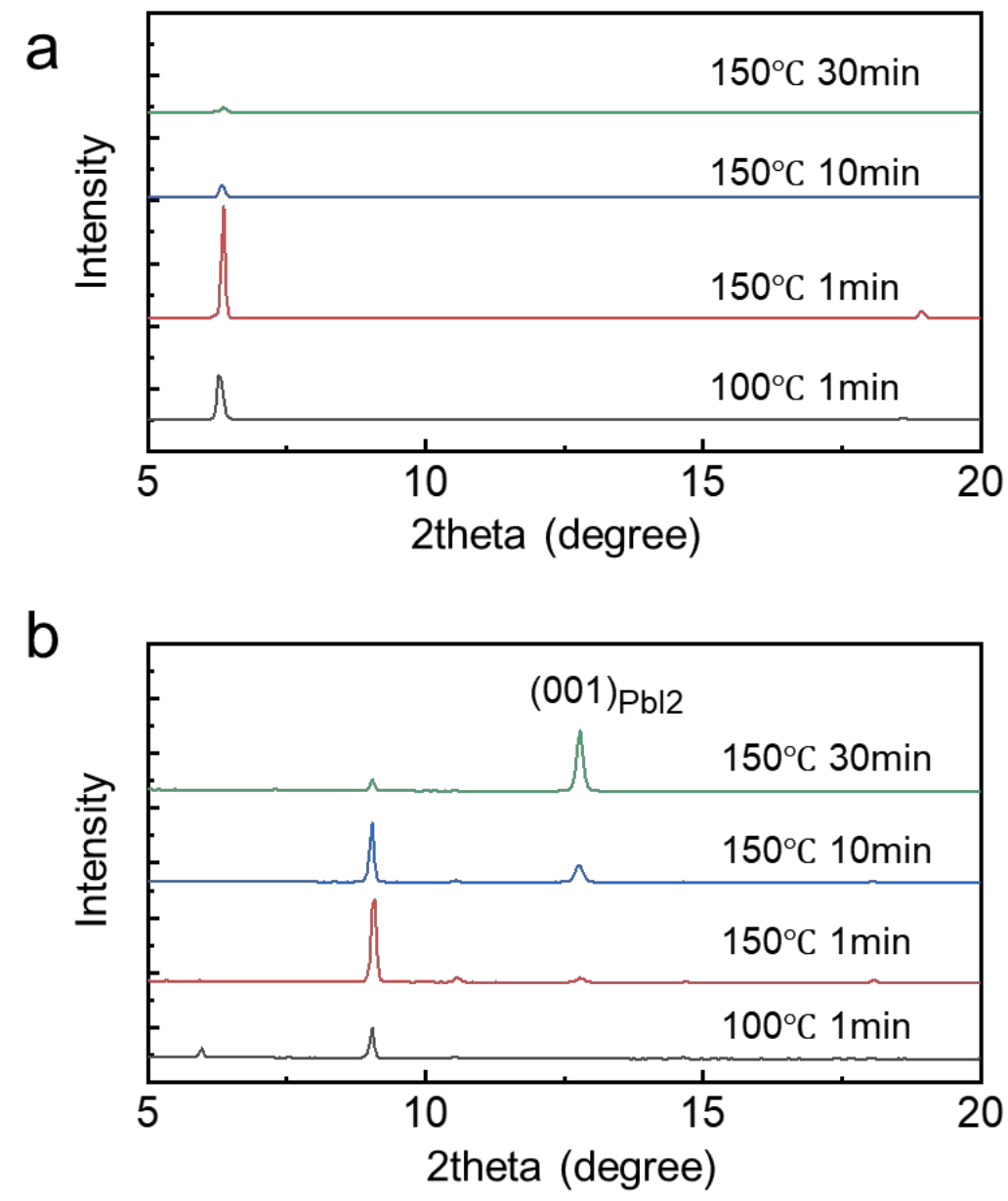

Figure S4. XRD patterns of (a) $\mathrm{MPMA}_{2} \mathrm{PbI}_{4}$ and (b) $\mathrm{DMPMA}_{2} \mathrm{PbI}_{4}$. Films were exposed to thermal stress in ambient air with relative humidity ranging from 25 to $35 \%$. 

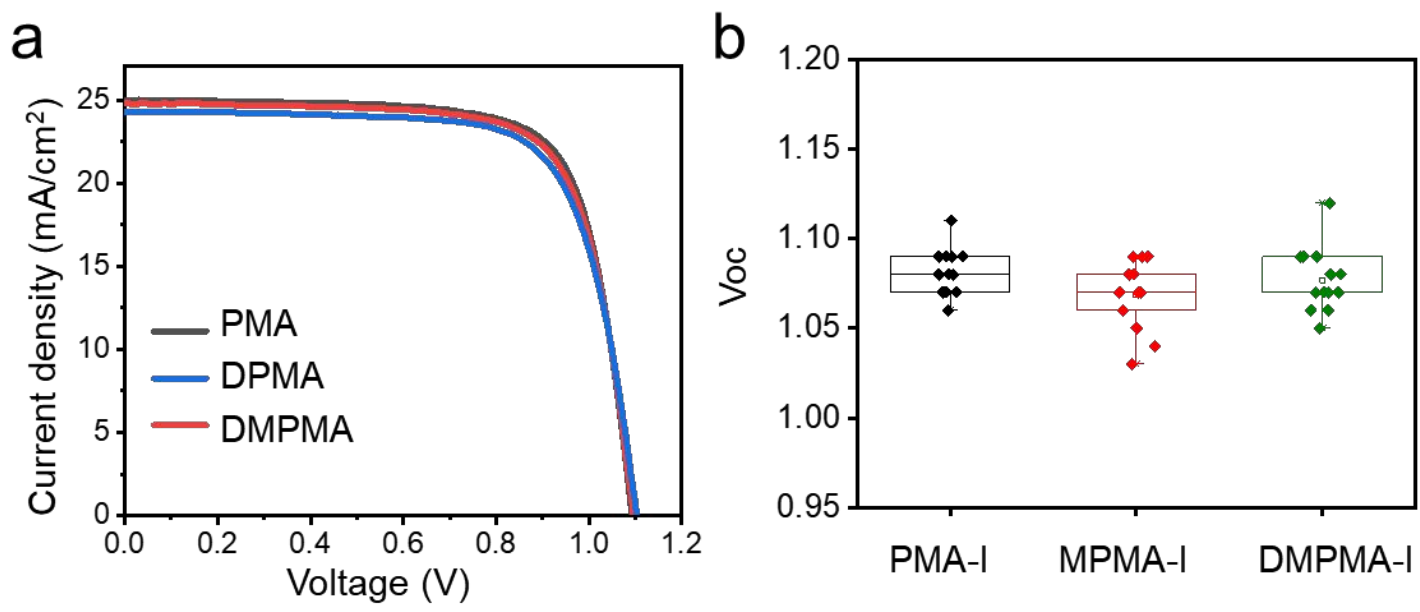

Figure S5. (a) J-V curves of PSCs with 0.5 mol\% PMA-I, MPMA-I and DMPMA-I. (b) Histogram of the Voc values. 

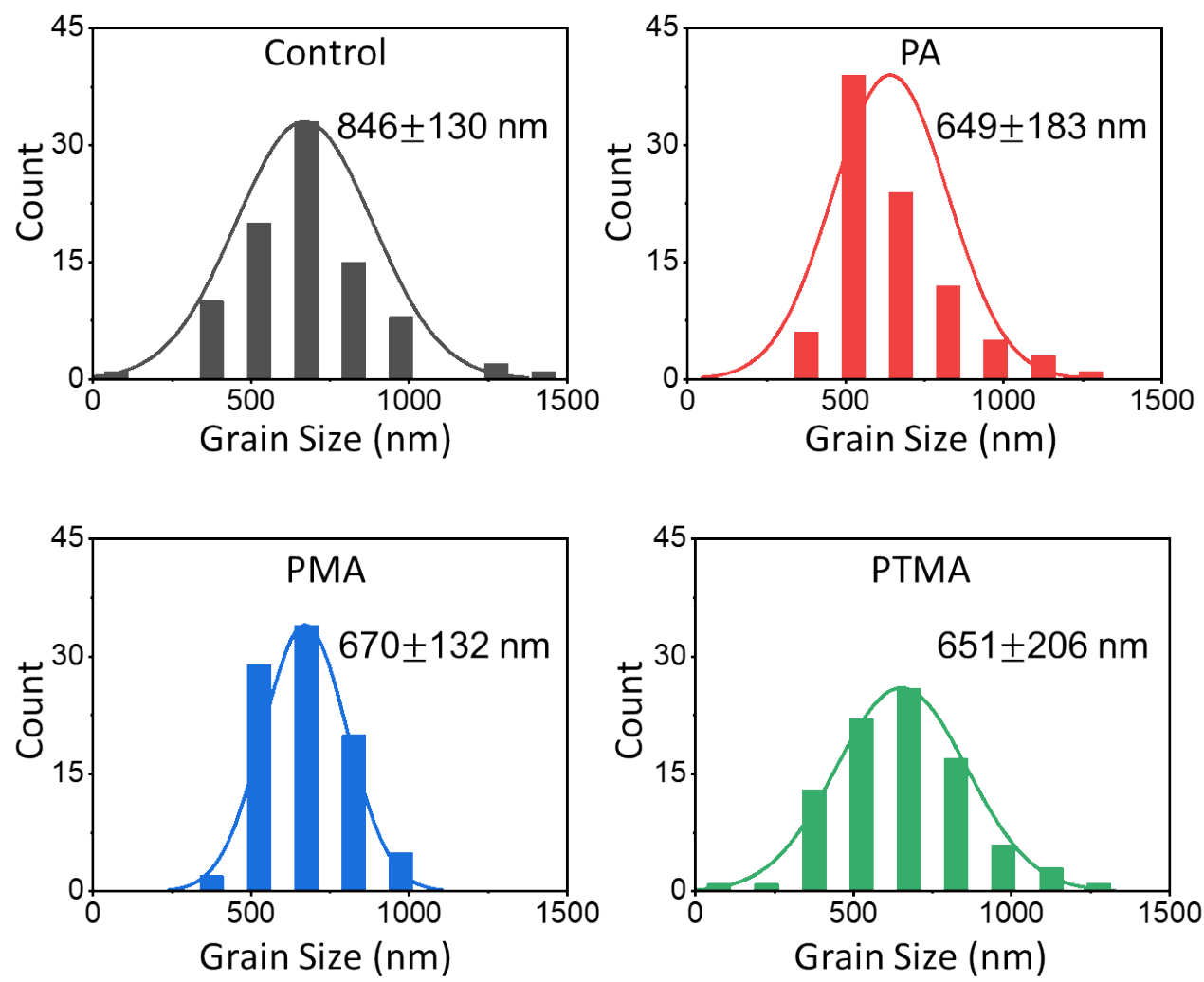

Figure S6. Grain size distribution of perovskite film 

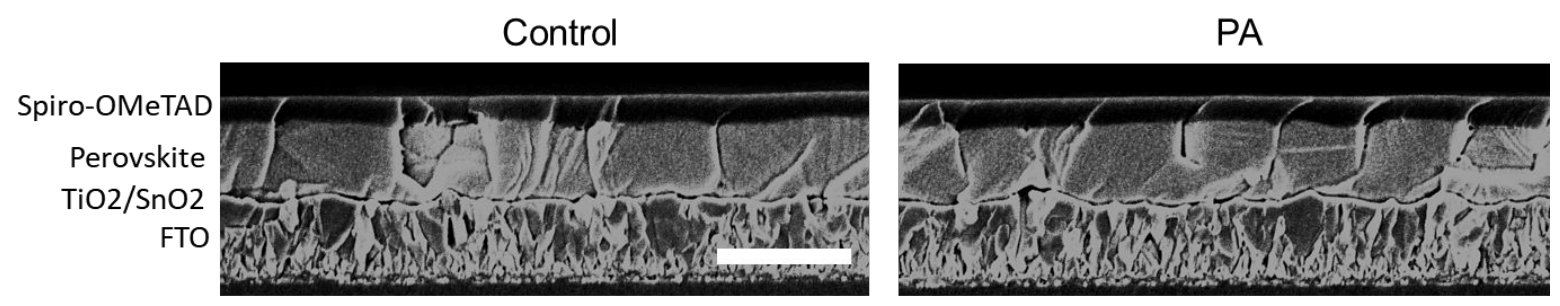

PMA

\section{PTMA}
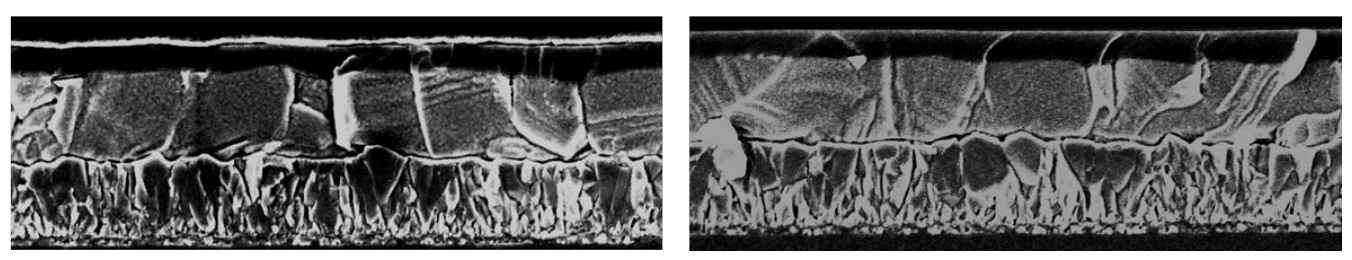

Figure S7. Cross-sectional SEM images of perovskite solar cell (scale bar $=1 \mu \mathrm{m})$. 

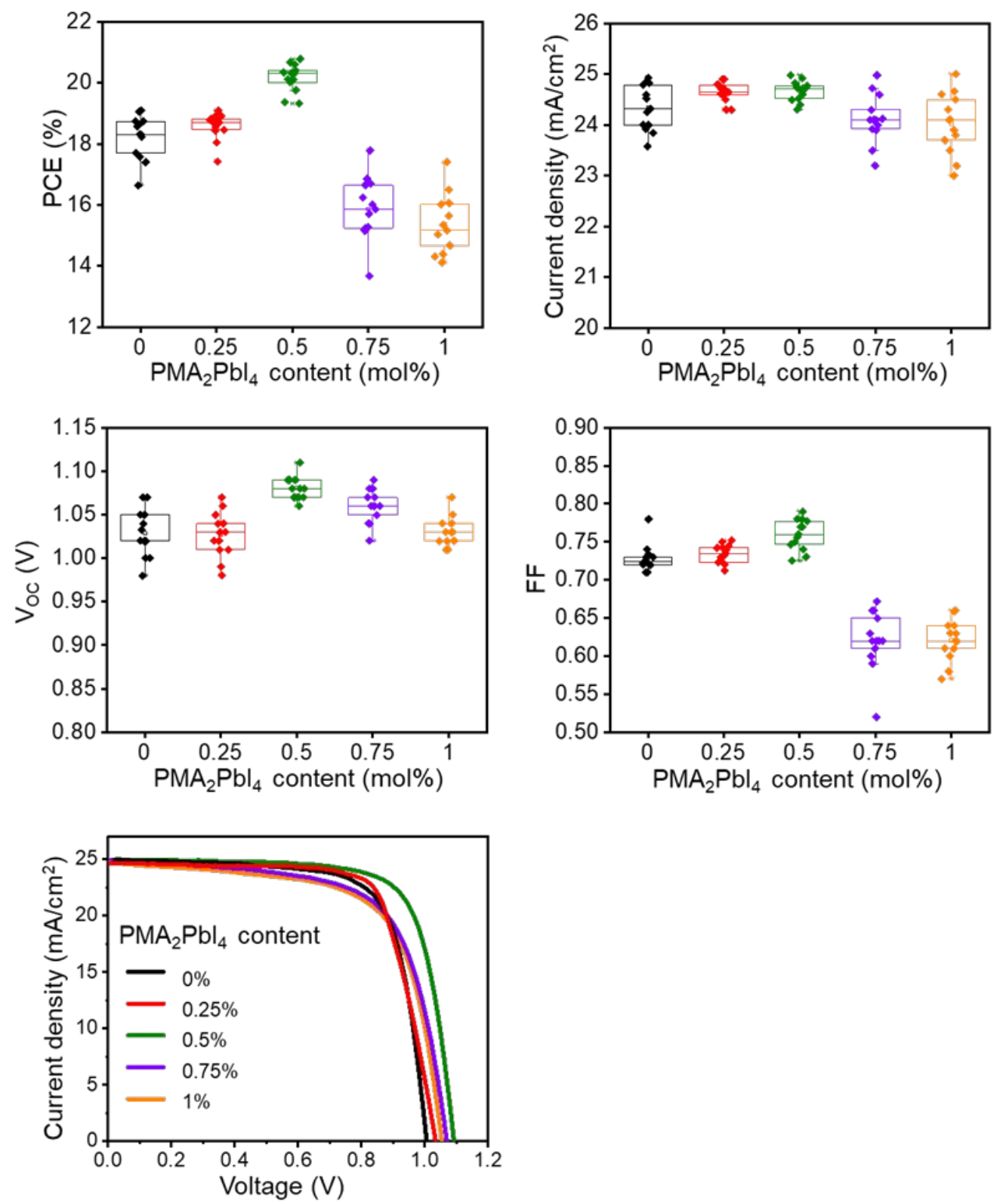

Figure S8. Effect of PMA-I content on photovoltaic parameters. Power conversion efficiency (PCE), fill factor (FF), short-circuit current density (Jsc), and open circuit voltage (Voc) of $(\mathrm{FAPbI})_{3.95}\left(\mathrm{MAPbBr}_{3}\right)_{0.05}$ with different amounts of added $\mathrm{PMA}_{2} \mathrm{PbI}_{4}$ perovskite. 

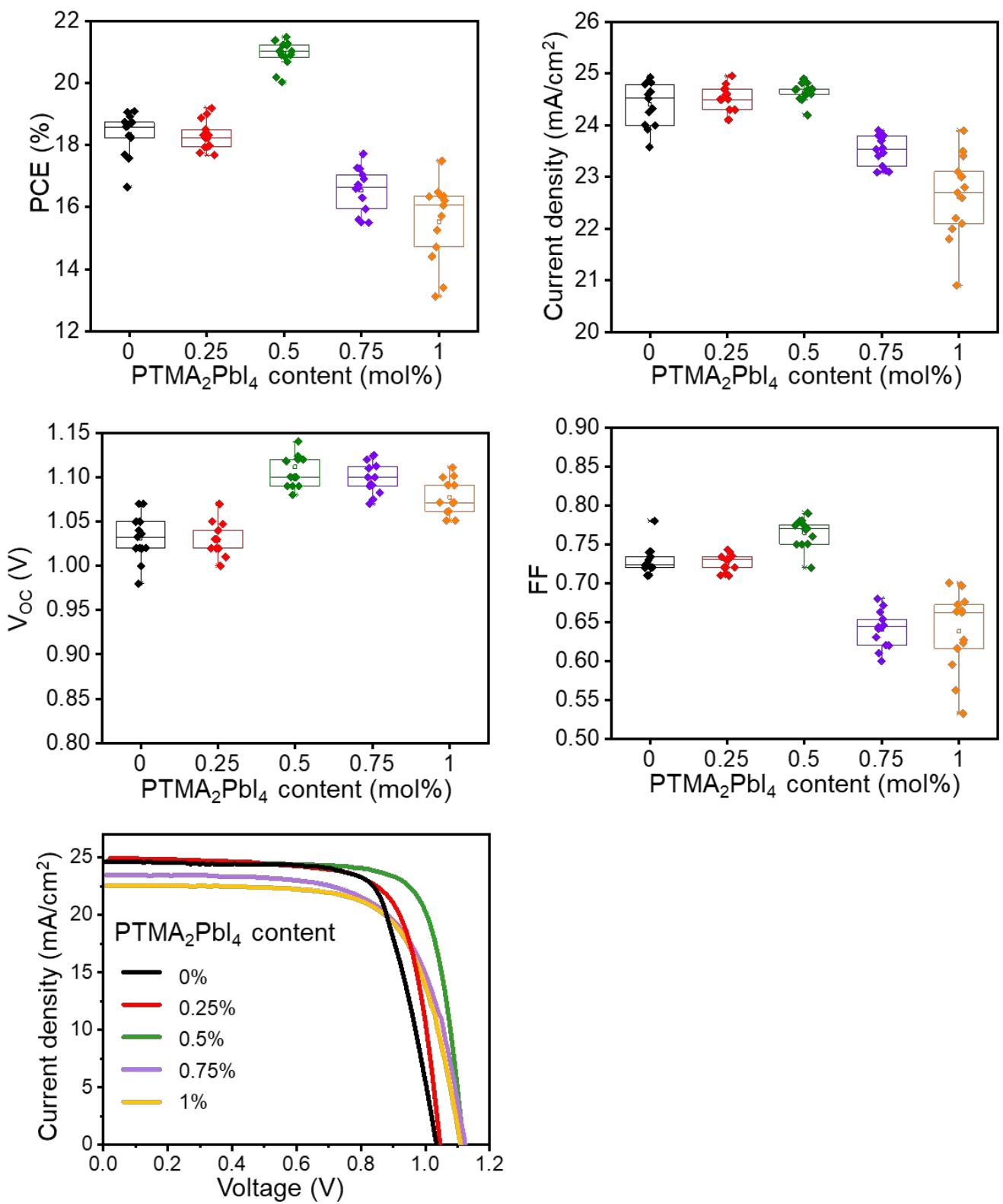

Figure S9. Effect of PTMA-I content on photovoltaic parameters. Power conversion efficiency (PCE), fill factor (FF), short-circuit current density (JSc), and open circuit voltage (Voc) of $\left(\mathrm{FAPbI}_{3}\right)_{0.95}\left(\mathrm{MAPbBr}_{3}\right)_{0.05}$ with different amounts of added $\mathrm{PTMA}_{2} \mathrm{PbI}_{4}$ perovskite. 

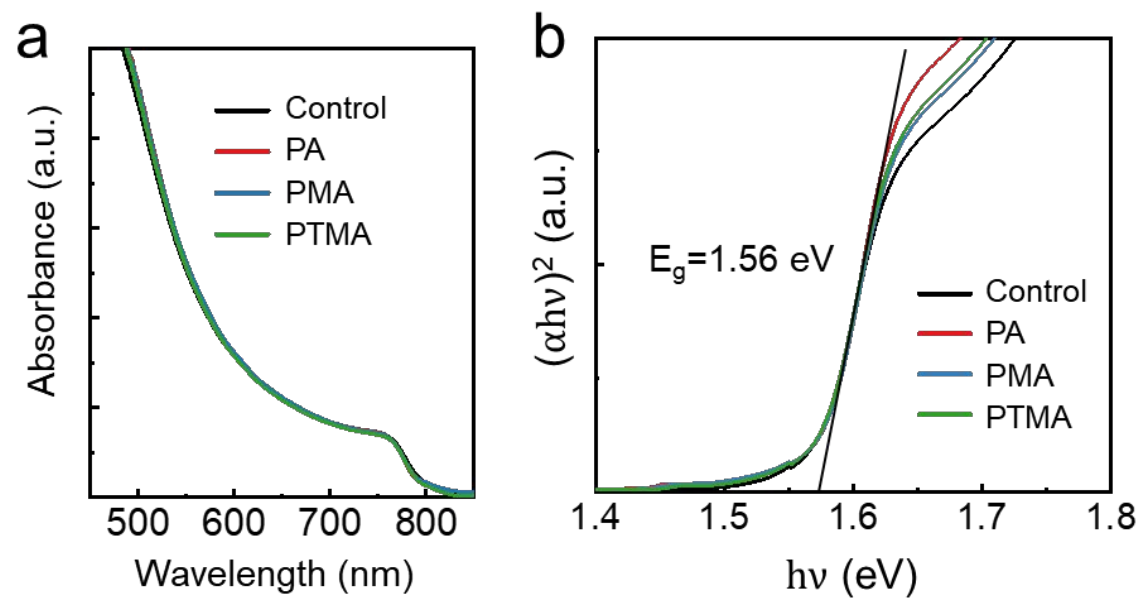

Figure S10. (a) The optical absorption spectra and (b) Tauc plots of perovskite films. 

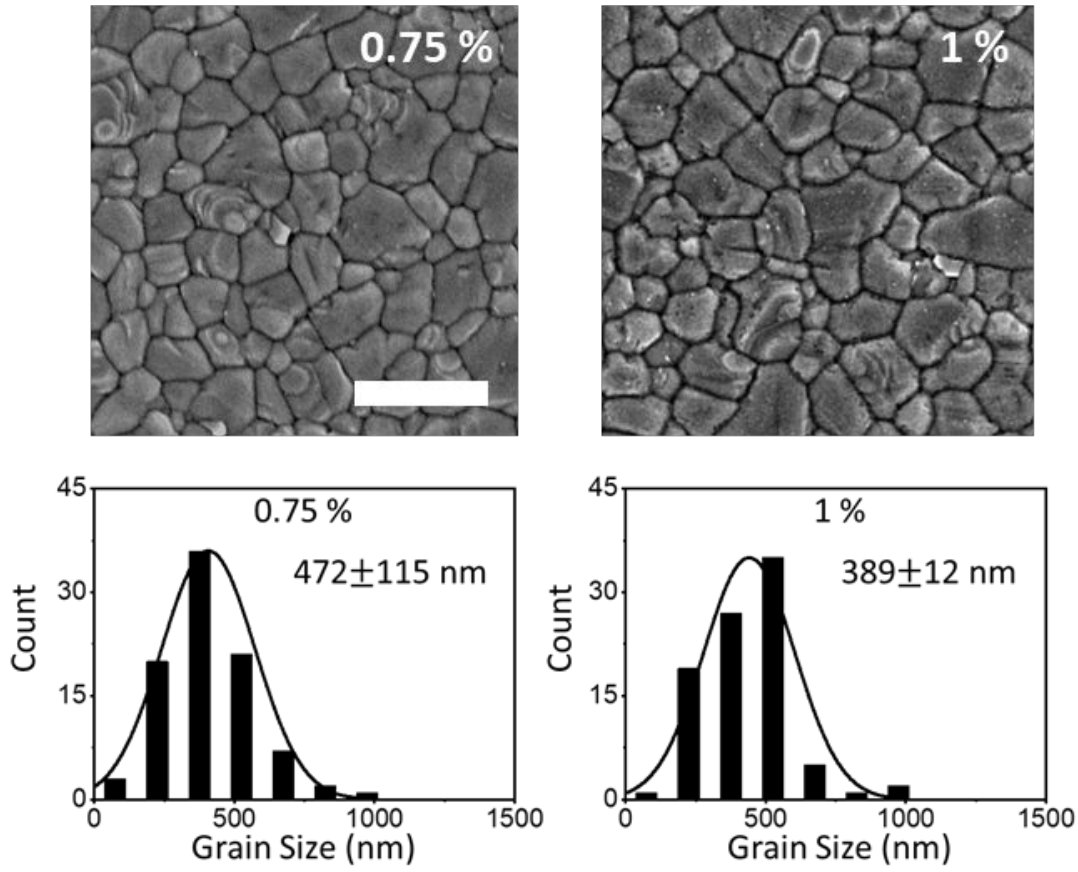

Figure S11. Planar SEM image of perovskite films incorporating $0.75 \mathrm{~mol} \%$ and $1 \mathrm{~mol} \%$ PTMA-I (Scale bar $=1 \mu \mathrm{m})$ 


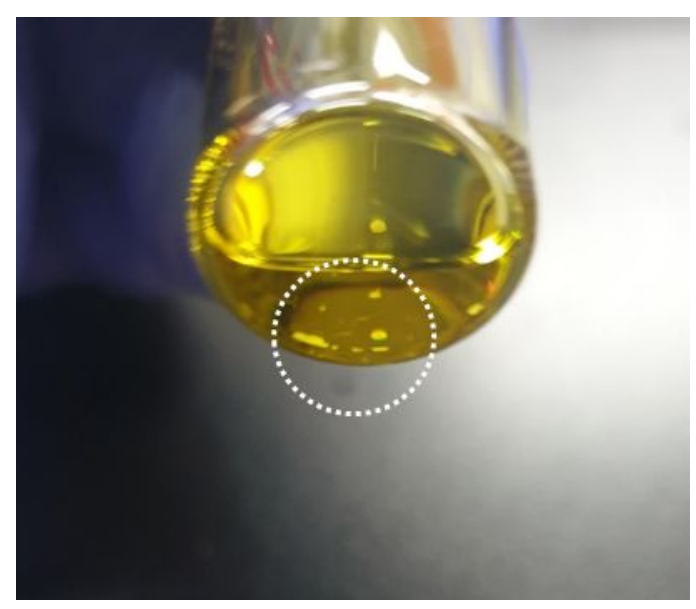

Figure S12. White precipitates start to form when $1 \mathrm{~mol} \%$ amount of PTMA-I salt is added to the solution. These precipitates are expected to be $\mathrm{PTMA}_{2} \mathrm{PbI}_{4}$. 

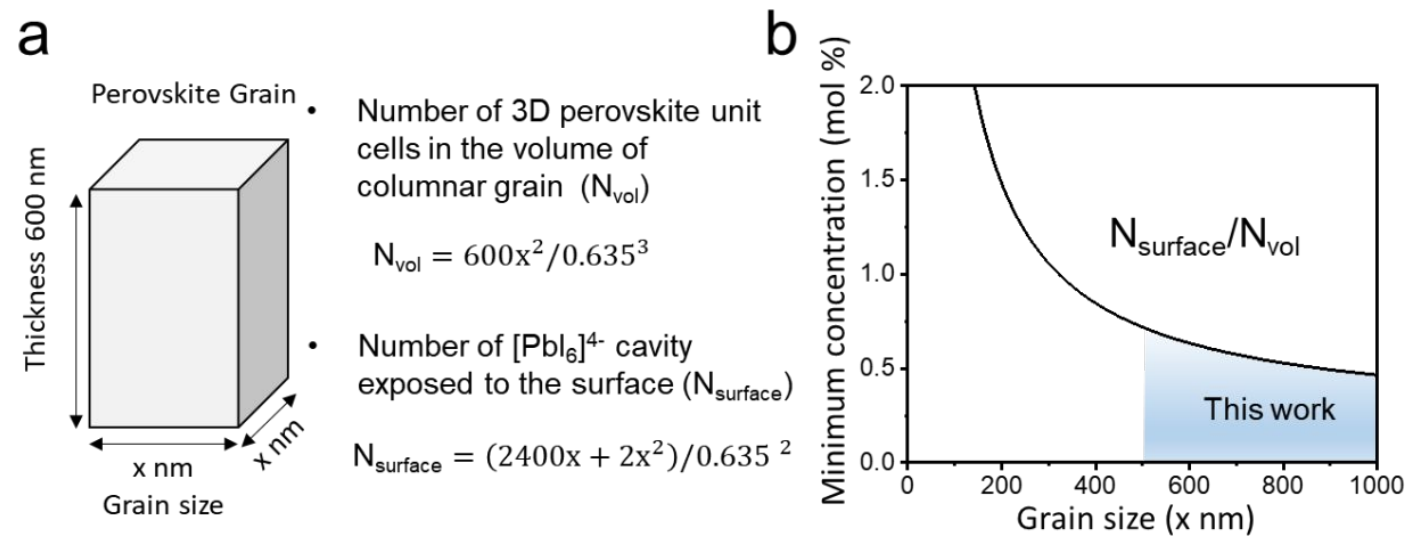

Figure S13. (a) Tetragonal perovskite grain used in the model calculation. (b) Minimum concentration of bulky organic cations required to cover the entire surface of $3 \mathrm{D}$ perovskite grain. 


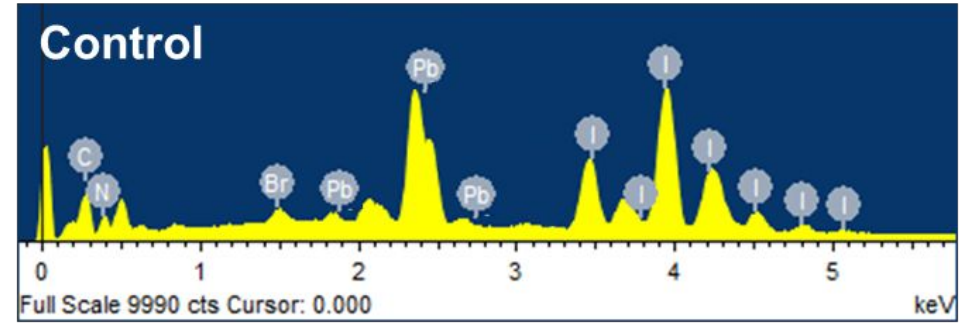

\begin{tabular}{c|c}
\hline Element & Atomic\% \\
\hline $\mathrm{C} \mathrm{K}$ & 38.58 \\
\hline $\mathrm{N} \mathrm{K}$ & 27.75 \\
\hline $\mathrm{Br} \mathrm{L}$ & 1.3 \\
\hline $\mathrm{I} \mathrm{L}$ & 23.91 \\
\hline $\mathrm{Pb} \mathrm{M}$ & 8.46 \\
\hline Total & 100.00 \\
\hline
\end{tabular}

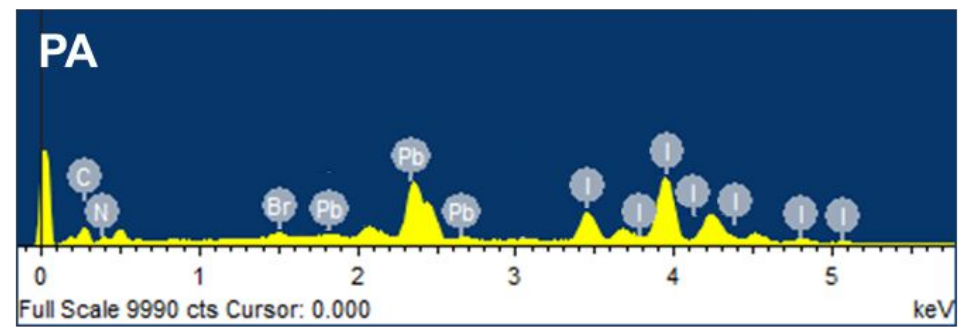

\begin{tabular}{c|c}
\hline Element & Atomic\% \\
\hline $\mathrm{C} \mathrm{K}$ & 35.93 \\
\hline $\mathrm{N} \mathrm{K}$ & 30.03 \\
\hline $\mathrm{Br} \mathrm{L}$ & 1.33 \\
\hline $\mathrm{I} \mathrm{L}$ & 23.43 \\
\hline $\mathrm{Pb} \mathrm{M}$ & 8.27 \\
\hline Total & 100.00 \\
\hline
\end{tabular}

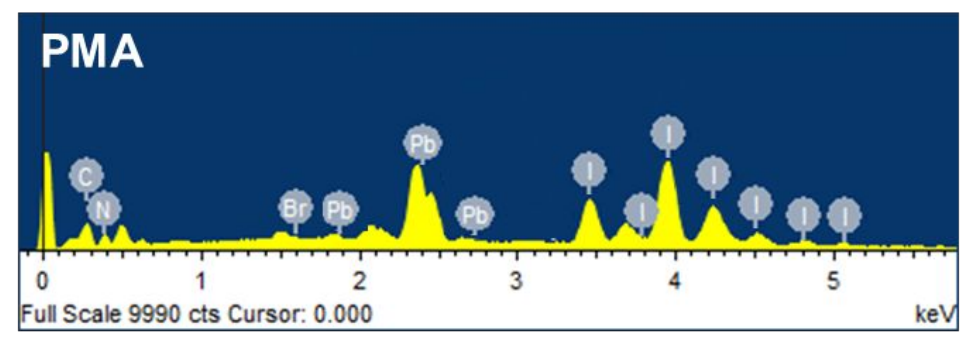

\begin{tabular}{c|c}
\hline Element & Atomic\% \\
\hline $\mathrm{C} \mathrm{K}$ & 37.27 \\
\hline $\mathrm{N} \mathrm{K}$ & 26.54 \\
\hline $\mathrm{Br} \mathrm{L}$ & 1.34 \\
\hline $\mathrm{I} \mathrm{L}$ & 25.22 \\
\hline $\mathrm{Pb} \mathrm{M}$ & 8.73 \\
\hline Total & 100.00 \\
\hline
\end{tabular}

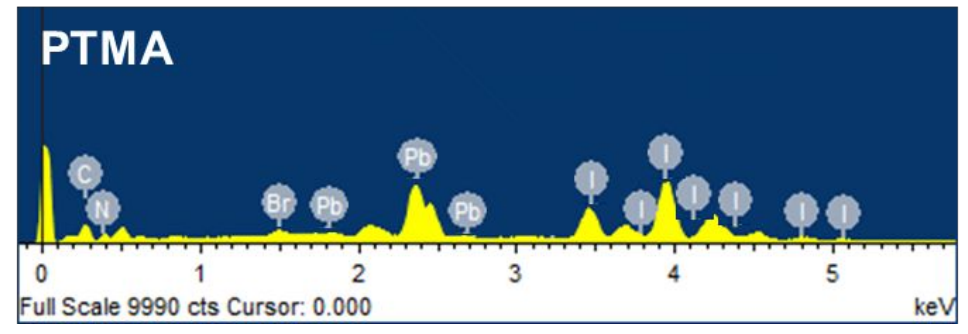

\begin{tabular}{c|c}
\hline Element & Atomic\% \\
\hline $\mathrm{C} \mathrm{K}$ & 37.11 \\
\hline $\mathrm{N} \mathrm{K}$ & 28.88 \\
\hline $\mathrm{Br} \mathrm{L}$ & 1.37 \\
$\mathrm{IL}$ & 24.38 \\
\hline $\mathrm{Pb} \mathrm{M}$ & 8.46 \\
\hline Total & 100.00 \\
\hline
\end{tabular}

Figure S14. EDS spectra of the perovskite films 

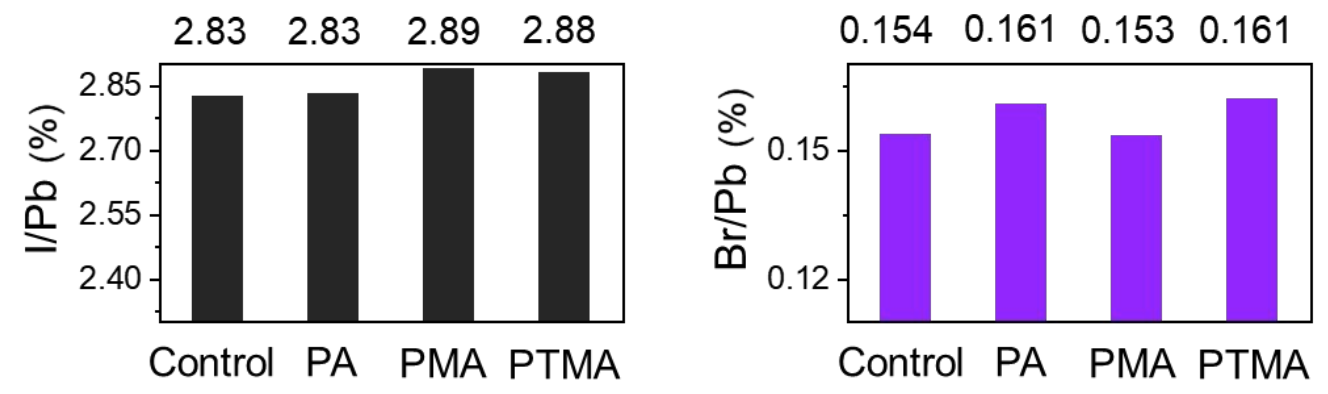

Figure S15. Elemental ratios obtained from the EDS spectrum 

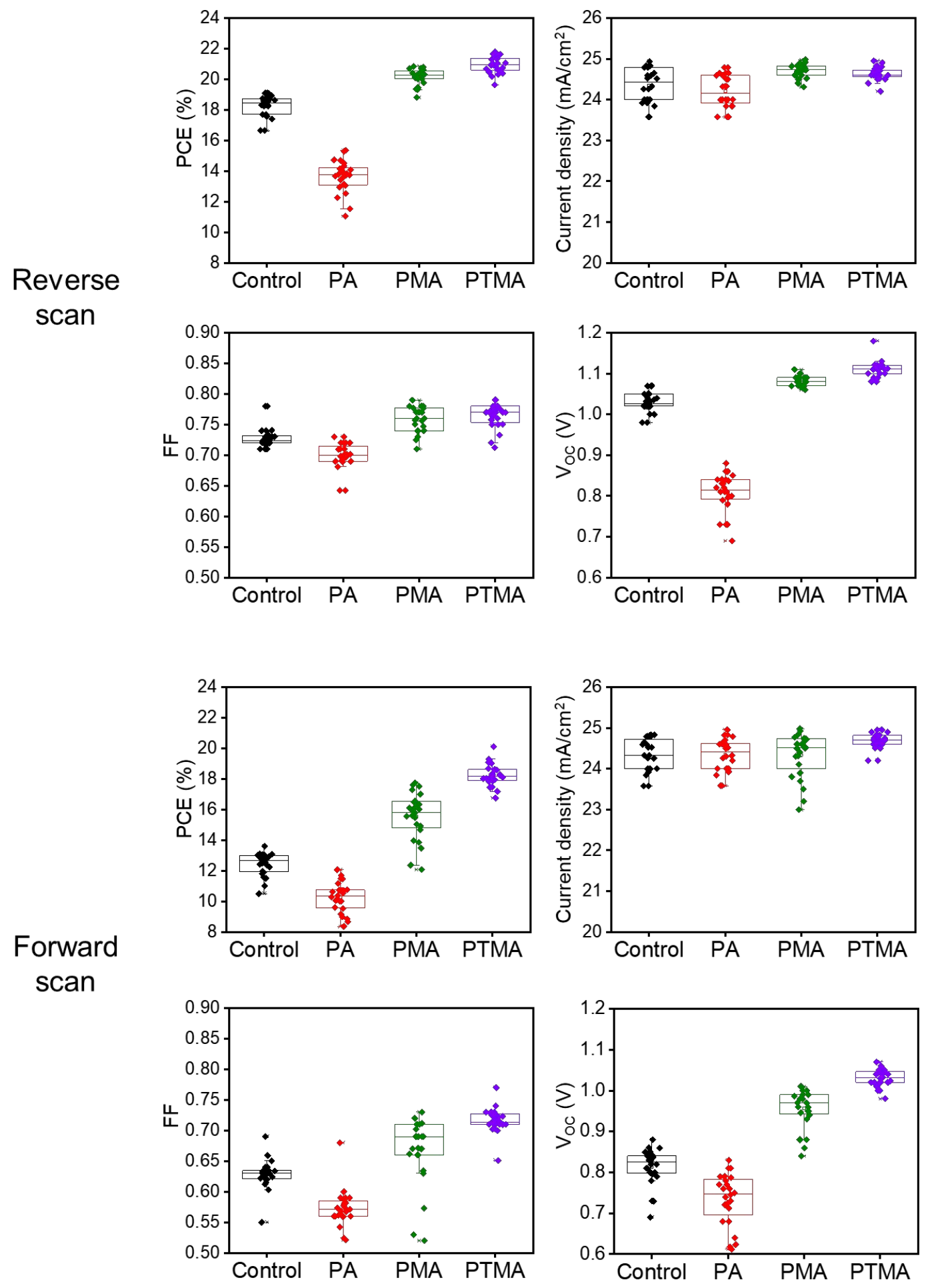

Figure S16. Distribution of photovoltaic performance of PSCs 

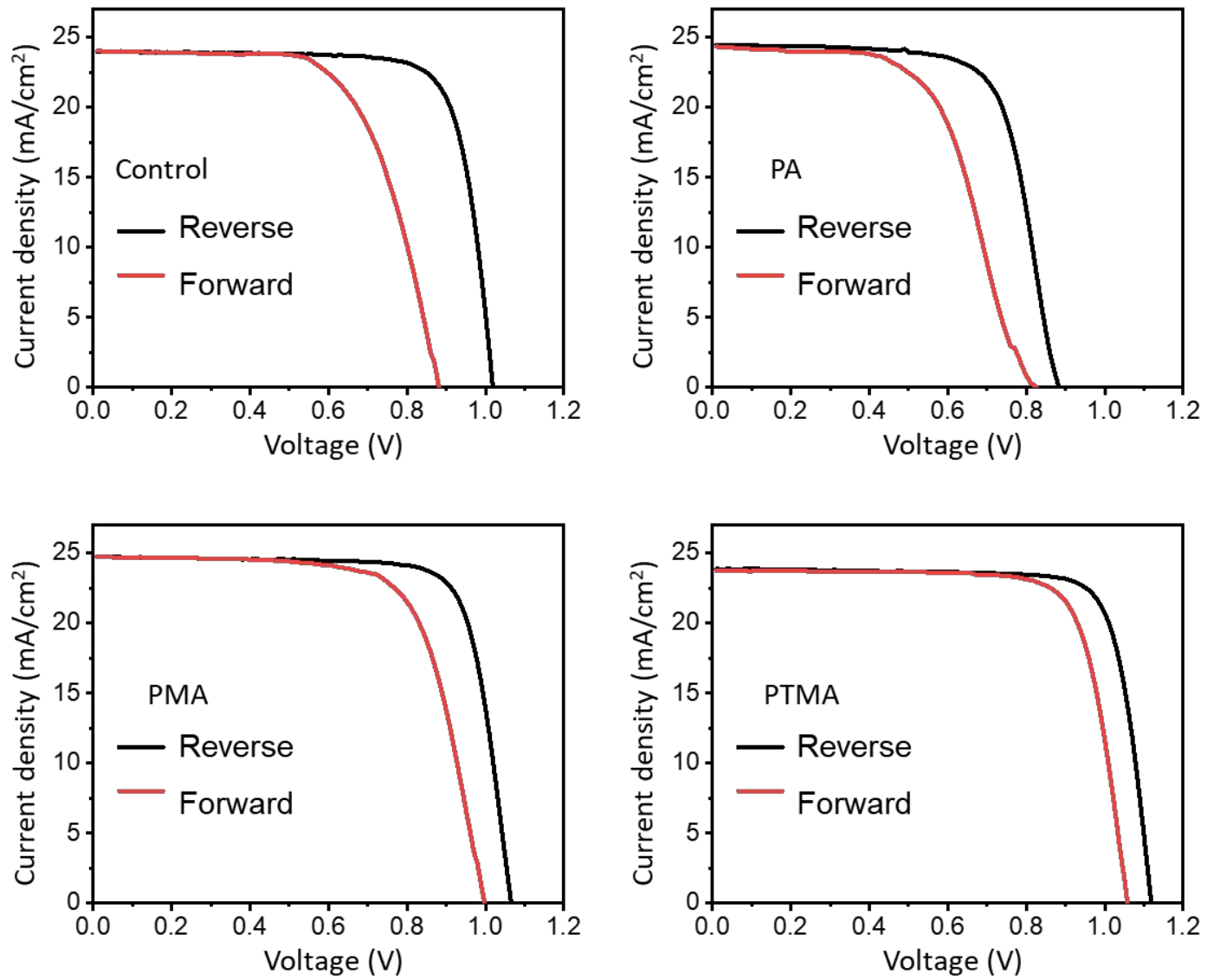

Figure S17. J-V curves of best performing PSCs recorded in both reverse and forward scan directions 


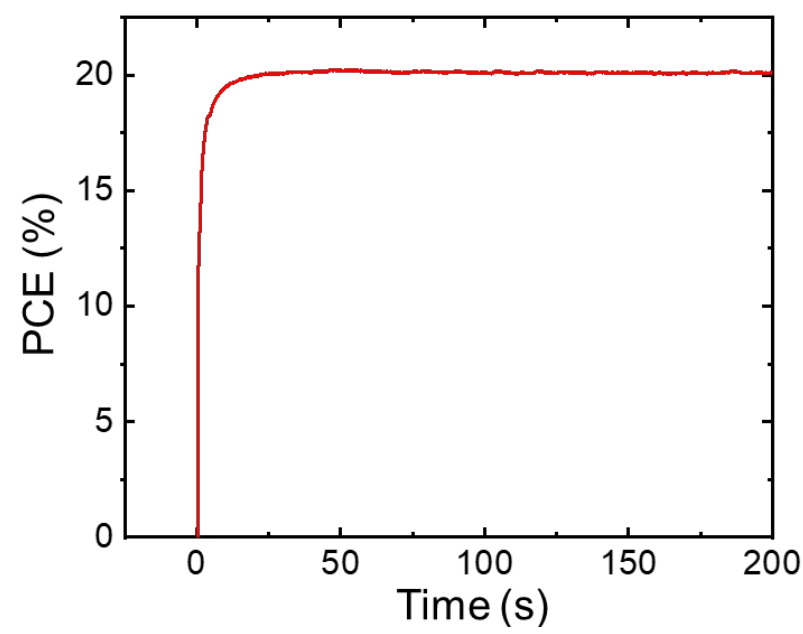

Figure S18. Steady-state PCE measurement of best performing PTMA-I added PSC. The deice was held at constant potential at maximum power point $\left(\mathrm{V}_{\text {app }}=1 \mathrm{~V}\right)$ to track the stabilized efficiency. 


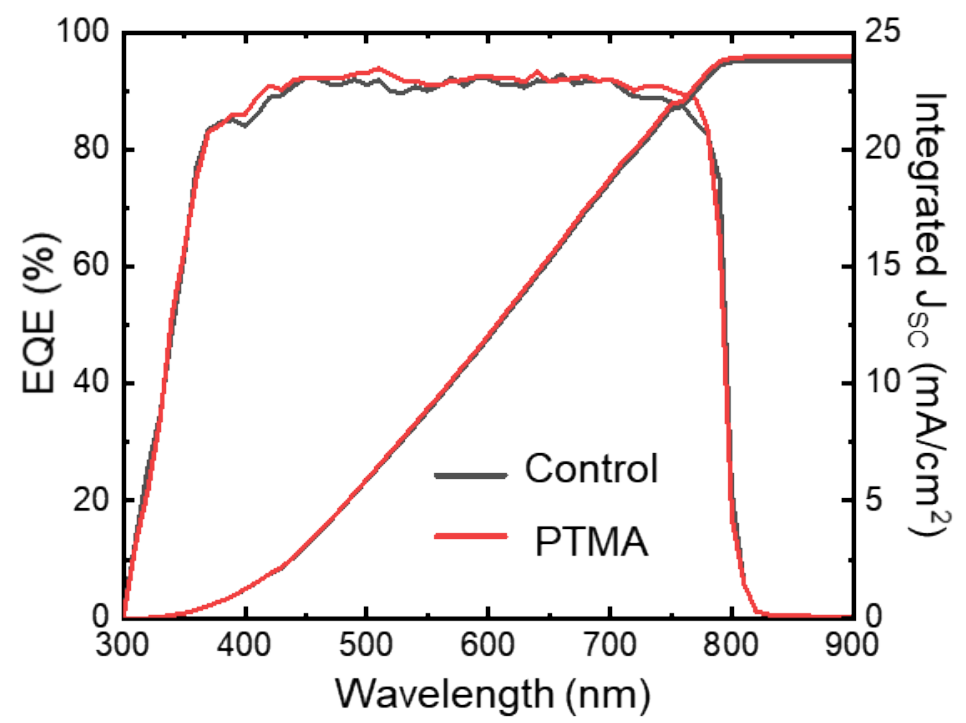

Figure S19. External quantum efficiency plot of PSCs. The integrated current density determined from EQE spectrum is also shown in the right axis. 

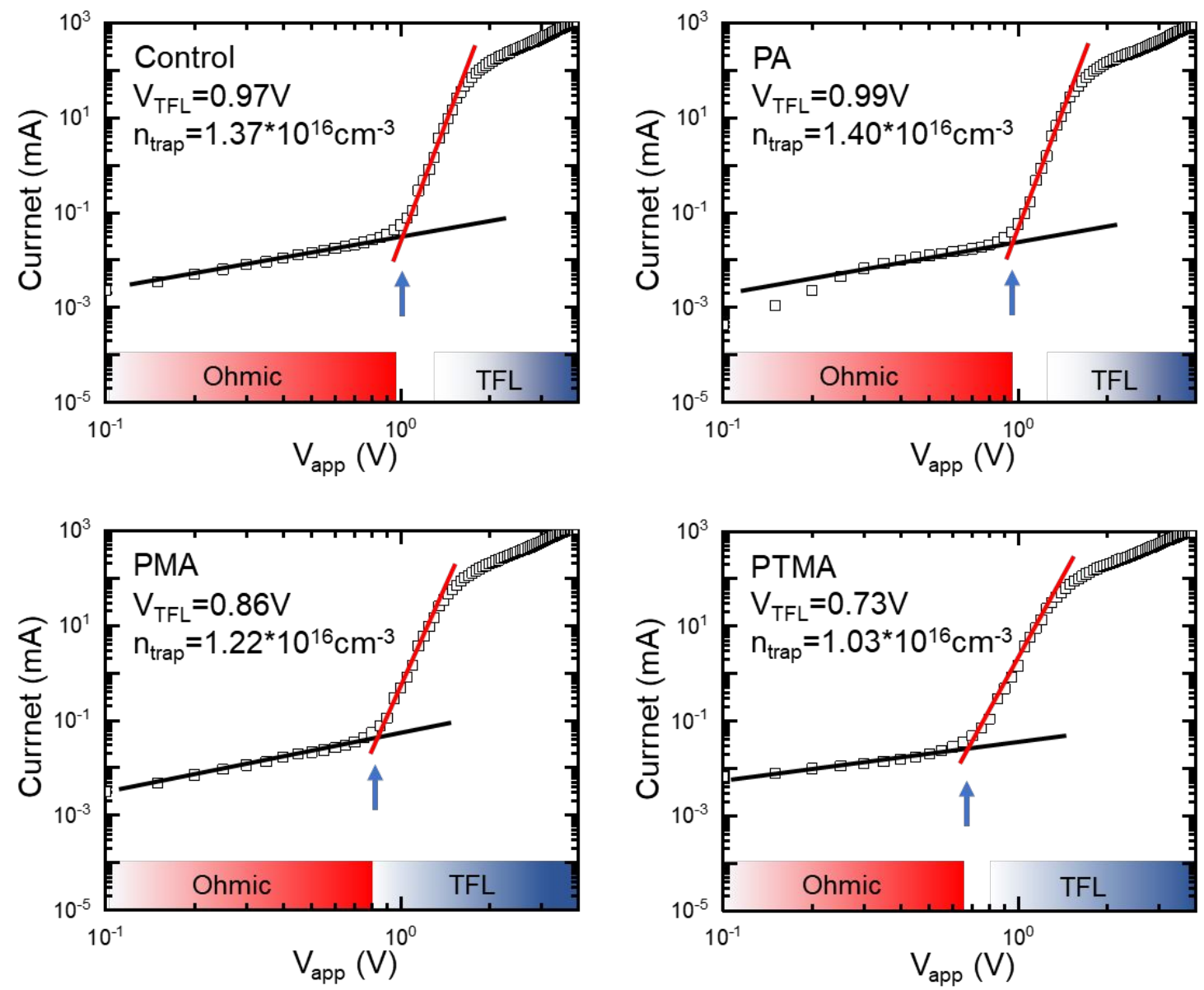

Figure S20. Dark current-voltage curves for electron-only devices, showing ohmic region with $\mathrm{n}=1$ and trap limited region with $\mathrm{n}>3$. 


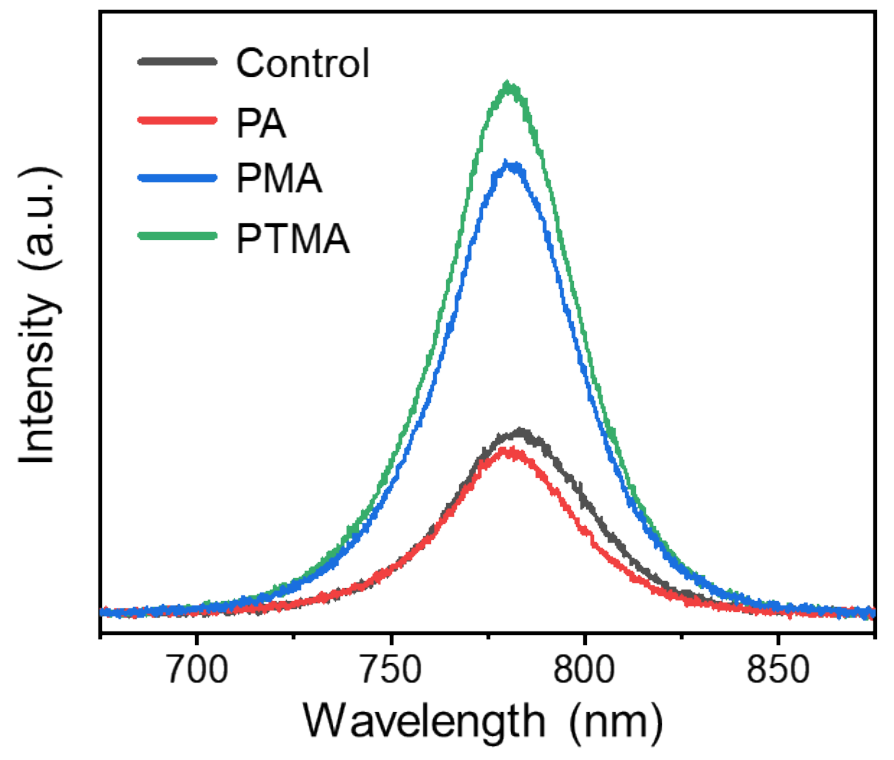

Figure S21. Steady state PL spectra of perovskite layer deposited on glass substrate 


\begin{tabular}{|c|}
\hline $\mathrm{Au}$ \\
\hline Spiro-OMeTAD \\
\hline Perovskite (surface) \\
\hline $\begin{array}{c}\text { Perovskite } \\
\text { (bulk) }\end{array}$ \\
\hline Perovskite (surface) \\
\hline SnO 2 \\
\hline FTO \\
\hline
\end{tabular}

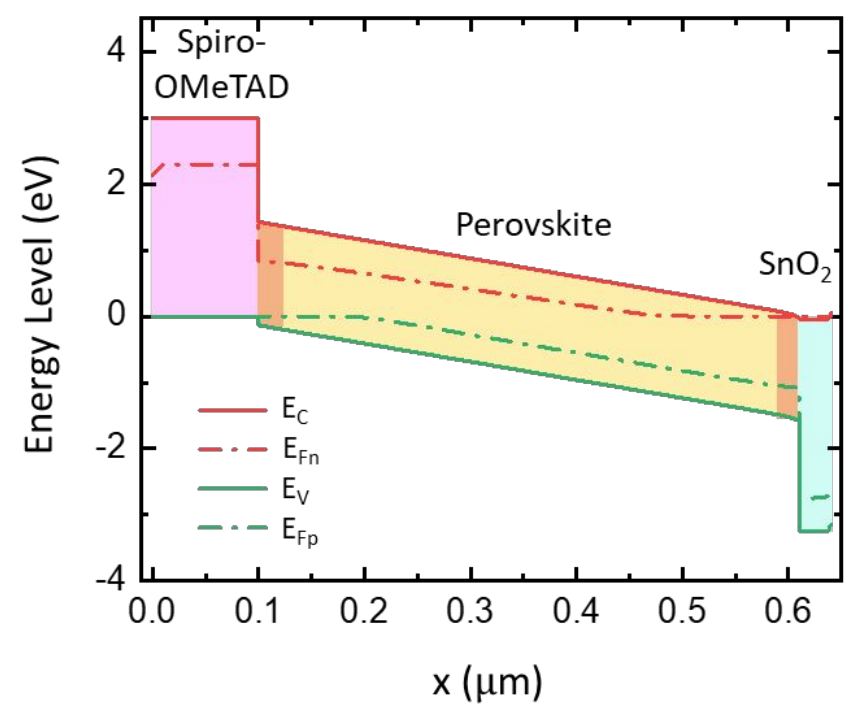

Figure S22. Schematic diagram of device layers defined for SCAPS-1D simulation. 

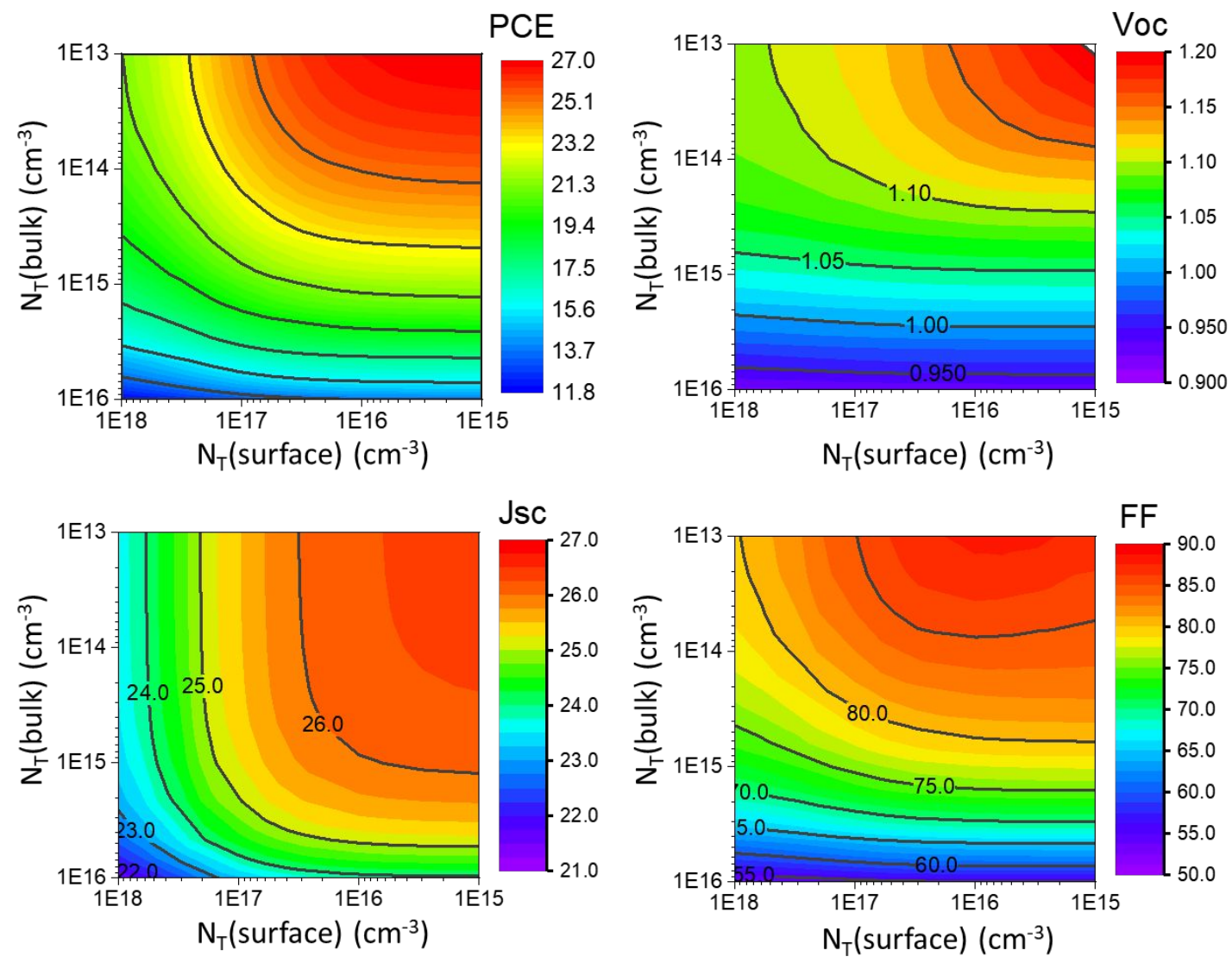

Figure S23. Simulation result of photovoltaic parameters with varying defect densities in perovskite films 

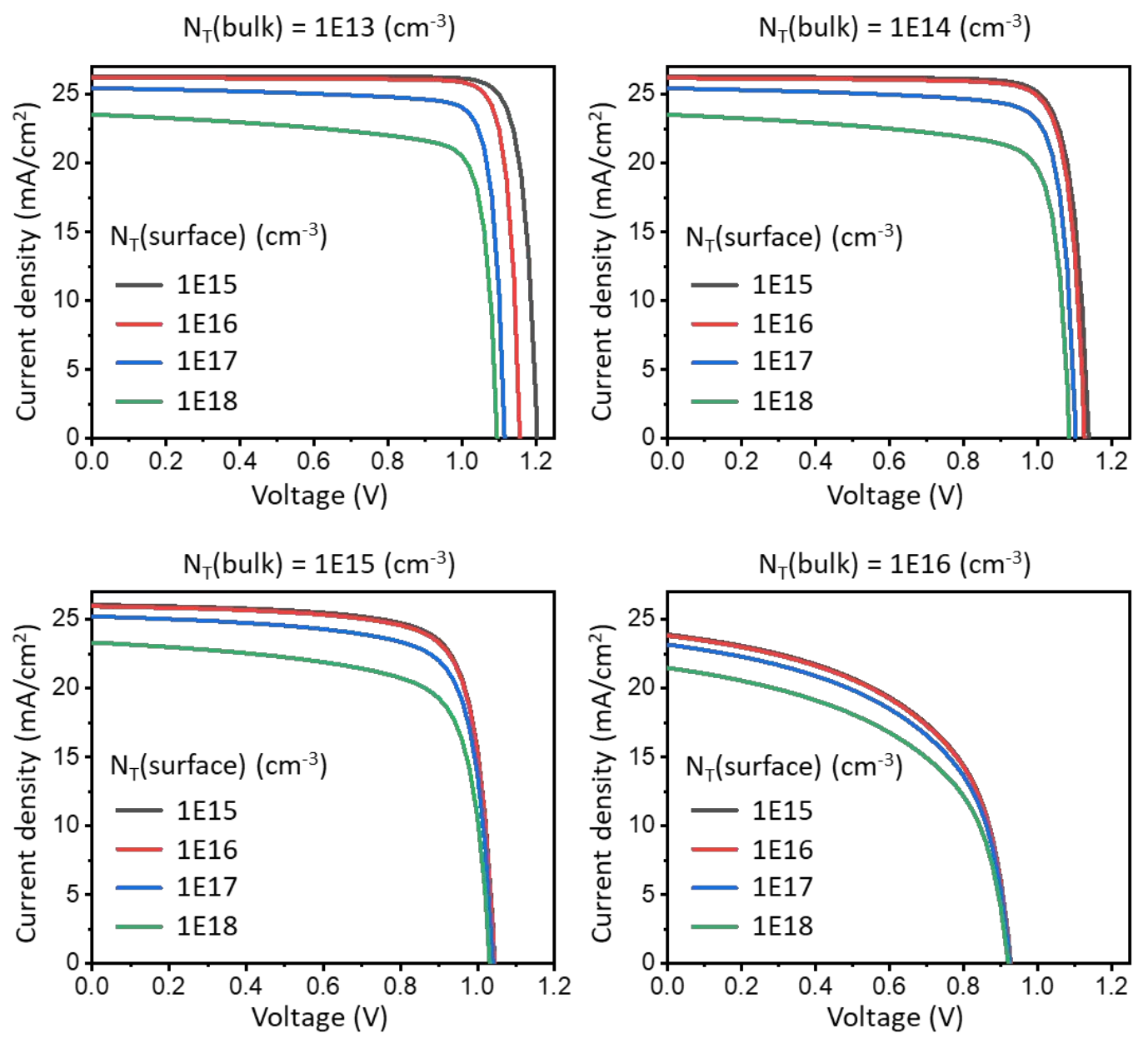

Figure S24. J-V curve of PSCs obtained from drift-diffusion model with varying defect densities 
Table S1. Photovoltaic characteristics of the best performing PSC

\begin{tabular}{|c|c|c|c|c|c|c|}
\hline & $\begin{array}{c}\text { Scan } \\
\text { direction }\end{array}$ & $\begin{array}{l}V_{o c} \\
\quad[\mathrm{~V}]\end{array}$ & $\begin{array}{l}J_{s c} \\
{\left[\mathrm{~mA} \mathrm{~cm}^{-2}\right]}\end{array}$ & $\mathrm{FF}$ & $\begin{array}{l}\mathrm{PCE} \\
{[\%]}\end{array}$ & HI \\
\hline \multirow[t]{2}{*}{ Control } & Reverse & 1.02 & 24.0 & 0.78 & 19.1 & \multirow[t]{2}{*}{0.29} \\
\hline & Forward & 0.88 & 24.0 & 0.64 & 13.6 & \\
\hline \multirow[t]{2}{*}{$\mathrm{PA}$} & Reverse & 0.88 & 24.5 & 0.71 & 15.3 & \multirow[t]{2}{*}{0.24} \\
\hline & Forward & 0.83 & 24.3 & 0.58 & 11.7 & \\
\hline \multirow[t]{2}{*}{ PMA } & Reverse & 1.07 & 24.8 & 0.77 & 20.4 & \multirow[t]{2}{*}{0.17} \\
\hline & Forward & 0.99 & 24.7 & 0.69 & 17.0 & \\
\hline \multirow[t]{2}{*}{ PTMA } & Reverse & 1.11 & 24.6 & 0.79 & 21.6 & \multirow[t]{2}{*}{0.05} \\
\hline & Forward & 1.06 & 24.6 & 0.77 & 20.6 & \\
\hline
\end{tabular}


Table S2. SCAPS-1D parameters for the perovskite solar cells

\begin{tabular}{|c|c|c|c|c|}
\hline Parameter & ETL $(\mathrm{SnO} 2)$ & $\begin{array}{l}\text { Perovskite } \\
\text { bulk }\end{array}$ & $\begin{array}{c}\text { Perovskite } \\
\text { surface }\end{array}$ & $\begin{array}{l}\text { HTL (Spiro- } \\
\text { OMeTAD) }\end{array}$ \\
\hline Thickness (nm) & 30 & 580 & 10 & 100 \\
\hline $\begin{array}{c}\mathrm{CB} / \mathrm{VB} \\
\text { effective DOS } \\
{\left[\mathrm{cm}^{-3}\right]}\end{array}$ & $\begin{array}{l}1.0 \mathrm{E} 18 \\
/ 1.0 \mathrm{E} 19\end{array}$ & $\begin{array}{c}1.0 \mathrm{E} 18 / 1.0 \\
\mathrm{E} 19^{[1]}\end{array}$ & $\begin{array}{l}1.0 \mathrm{E} 18 \\
/ 1.0 \mathrm{E} 19\end{array}$ & $\begin{array}{l}1.0 \mathrm{E} 18 \\
/ 1.0 \mathrm{E} 19\end{array}$ \\
\hline $\begin{array}{c}\text { Acceptor/ } \\
\text { donor } \\
\text { concentration } \\
{\left[\mathrm{cm}^{-3}\right]}\end{array}$ & $\begin{array}{l}1.0 \mathrm{E} 18 \\
/ 1.0 \mathrm{E} 19\end{array}$ & $\begin{array}{c}1.0 \mathrm{E} 14 \\
/ 1.0 \mathrm{E} 14^{[2]}\end{array}$ & $\begin{array}{l}1.0 \mathrm{E} 14 \\
/ 1.0 \mathrm{E} 14\end{array}$ & $\begin{array}{l}1.0 \mathrm{E} 19 \\
/ 1.0 \mathrm{E} 18\end{array}$ \\
\hline $\begin{array}{r}\text { Dielectric } \\
\text { constant }\end{array}$ & 9 & 22 & 22 & 3 \\
\hline $\begin{array}{c}\text { Electron } \\
\text { affinity }[\mathrm{eV}]\end{array}$ & 4.0 & 3.95 & 3.95 & 2.4 \\
\hline Band gap $[\mathrm{eV}]$ & 3.2 & 1.54 & 1.54 & 3 \\
\hline $\begin{array}{c}\text { Electron/hole } \\
\text { mobility } \\
{\left[\mathrm{cm}^{2} \mathrm{~V}^{-1} \mathrm{~S}^{-1}\right]}\end{array}$ & $\begin{array}{l}5.0 \mathrm{E}-2 \\
/ 5.0 \mathrm{E}-3\end{array}$ & $4 / 4$ & $2 / 2$ & $\begin{array}{l}5.000 \mathrm{E}-4 \\
/ 5.000 \mathrm{E}-4\end{array}$ \\
\hline Defect type & $\begin{array}{c}\text { Neutral } \\
\text { (Gaussian) }\end{array}$ & $\begin{array}{c}\text { Neutral } \\
\text { (Gaussian) }\end{array}$ & $\begin{array}{l}\text { Neutral } \\
\text { (Gaussian) }\end{array}$ & $\begin{array}{c}\text { Neutral } \\
\text { (Gaussian) }\end{array}$ \\
\hline $\mathrm{Et}(\mathrm{eV}) / \mathrm{Ech}$ & $0.5 / 0.1$ & $0.5 / 0.1^{[2]}$ & $0.5 / 0.1$ & $0.5 / 0.1$ \\
\hline Trap density & $1.0 \mathrm{E} 16$ & $\begin{aligned} & 1.0 \mathrm{E} 14 \\
& \sim 5.0 \mathrm{E} 15^{[3]} \\
& \text { (variable) }\end{aligned}$ & $\begin{array}{c}1.0 \mathrm{E} 15 \\
\sim 1.0 \mathrm{E} 20^{[3]} \\
\text { (variable) }\end{array}$ & $1.0 \mathrm{E} 15$ \\
\hline $\begin{array}{l}\text { Capture Aross } \\
\text { Section for } \\
\text { Electrons and } \\
\text { Holes }\left(\mathrm{cm}^{2}\right)\end{array}$ & $\begin{array}{c}5.0 \text { E-14 } \\
/ 5.0 \text { E-14 }\end{array}$ & $\begin{array}{c}5.0 \mathrm{E}-14 \\
/ 5.0 \mathrm{E}-14^{[2]}\end{array}$ & $\begin{array}{l}5.0 \mathrm{E}-14 \\
/ 5.0 \mathrm{E}-14\end{array}$ & $\begin{array}{l}5.0 \mathrm{E}-14 \\
/ 5.0 \mathrm{E}-14\end{array}$ \\
\hline
\end{tabular}


Table S3. Photovoltaic parameters for the simulated J-V curves

\begin{tabular}{cccccc}
\hline $\begin{array}{c}\mathrm{N}_{\mathrm{T}}(\text { bulk }) \\
{\left[\mathrm{cm}^{-3}\right]}\end{array}$ & $\begin{array}{c}\mathrm{N}_{\mathrm{T}}(\text { surface }) \\
{\left[\mathrm{cm}^{-3}\right]}\end{array}$ & $\begin{array}{c}V_{o c} \\
{[\mathrm{~V}]}\end{array}$ & $\begin{array}{c}J_{s c} \\
{\left[\mathrm{~mA} \mathrm{~cm}^{-2}\right]}\end{array}$ & FF & $\begin{array}{c}\mathrm{PCE} \\
{[\%]}\end{array}$ \\
\hline \multirow{2}{*}{$1 \mathrm{E} 13$} & $1 \mathrm{E} 15$ & 1.20 & 26.3 & 0.87 & 27.6 \\
& $1 \mathrm{E} 16$ & 1.16 & 26.2 & 0.87 & 26.6 \\
& $1 \mathrm{E} 17$ & 1.11 & 25.5 & 0.84 & 24.1 \\
& $1 \mathrm{E} 18$ & 1.09 & 23.6 & 0.79 & 20.6 \\
$1 \mathrm{E} 14$ & $1 \mathrm{E} 15$ & 1.14 & 26.3 & 0.84 & 25.2 \\
& $1 \mathrm{E} 16$ & 1.13 & 26.2 & 0.84 & 24.9 \\
& $1 \mathrm{E} 17$ & 1.10 & 25.4 & 0.82 & 23.1 \\
& $1 \mathrm{E} 18$ & 1.08 & 23.5 & 0.78 & 19.9 \\
$1 \mathrm{E} 15$ & $1 \mathrm{E} 15$ & 1.05 & 26.1 & 0.78 & 21.1 \\
& $1 \mathrm{E} 16$ & 1.04 & 25.9 & 0.77 & 21.0 \\
& $1 \mathrm{E} 17$ & 1.04 & 25.2 & 0.75 & 19.8 \\
& $1 \mathrm{E} 18$ & 1.03 & 23.3 & 0.72 & 17.4 \\
$1 \mathrm{E} 16$ & $1 \mathrm{E} 15$ & 0.93 & 23.9 & 0.55 & 12.2 \\
& $1 \mathrm{E} 16$ & 0.93 & 23.8 & 0.55 & 12.1 \\
& $1 \mathrm{E} 17$ & 0.92 & 23.2 & 0.54 & 11.6 \\
& $1 \mathrm{E} 18$ & 0.92 & 21.5 & 0.53 & 10.5 \\
\hline
\end{tabular}


Table S4. Summary of photovoltaic parameters and operational stability of perovskite solar cells reported in literature.

\begin{tabular}{|c|c|c|c|c|c|}
\hline Year & Perovskite & Test condition & $\begin{array}{l}\text { Initial PCE } \\
(\%)\end{array}$ & $\mathrm{T}_{80}(\mathrm{hrs})$ & Reference \\
\hline 2020 & $\left(\mathrm{FAPbl}_{3}\right)_{0.95}\left(\mathrm{MAPbBr}_{3}\right)_{0.05}$ & $\begin{array}{l}1 \text { Sun, RT, open- } \\
\text { circuit }\end{array}$ & $\sim 21$ & 1163 & This work \\
\hline 2018 & $\mathrm{GUA}_{0.15} \mathrm{MA}_{0.85} \mathrm{Pbl}_{3}$ & $\begin{array}{c}\text { 1Sun, } 60^{\circ} \mathrm{C}, \mathrm{MPP} \\
\text { tracking }\end{array}$ & $\sim 18$ & 63 & (4) \\
\hline 2017 & $\mathrm{Cs}_{0.1} \mathrm{FA}_{0.74} \mathrm{MA}_{0.13} \mathrm{Pbl}_{2.48} \mathrm{Br}_{0}$ & $\begin{array}{l}1 \text { Sun, RT, MPP } \\
\text { tracking }\end{array}$ & $\sim 20$ & 450 & (5) \\
\hline 2018 & $\mathrm{MAPbl}_{3}$ & $\begin{array}{l}1 \text { Sun, RT, epen- } \\
\text { circuit }\end{array}$ & $\sim 19$ & 391 & (6) \\
\hline 2019 & $\mathrm{MAPbl}_{3}$ & $\begin{array}{l}1 \text { Sun, RT, MPP } \\
\text { tracking }\end{array}$ & $\sim 19$ & 400 & (7) \\
\hline 2018 & $\mathrm{CS}_{0.1} \mathrm{FA}_{0.78} \mathrm{MA}_{0.12} \mathrm{Pbl}_{2.55} \mathrm{Br}_{0}$ & $\begin{array}{l}1 \text { Sun, RT, MPP } \\
\text { tracking }\end{array}$ & $\sim 20$ & 180 & (8) \\
\hline 2019 & $\mathrm{MAPbl}_{3}$ & $\begin{array}{l}1 \text { Sun, RT, MPP } \\
\text { tracking }\end{array}$ & $\sim 21$ & 810 & (9) \\
\hline 2020 & $\begin{array}{c}\mathrm{Cs}_{0.05}\left(\mathrm{MA}_{0.15} \mathrm{FA}_{0.85}\right)_{0.95} \mathrm{~Pb}(\mathrm{~B} \\
\left.\mathrm{r}_{0.15} \mathrm{I}_{0.85}\right)_{3}\end{array}$ & $\begin{array}{l}1 \text { Sun, RT, MPP } \\
\text { tracking }\end{array}$ & $\sim 21$ & 1300 & (10) \\
\hline 2018 & $\mathrm{Cs}_{0.05} \mathrm{FA}_{0.7} \mathrm{MA}_{0.25} \mathrm{Pbl}_{3}$ & $\begin{array}{l}1 \text { Sun, RT, epen- } \\
\text { circuit }\end{array}$ & $\sim 20$ & 2400 & (11) \\
\hline
\end{tabular}




\section{Supplementary References}

(1) Umari, P.; Mosconi, E.; De Angelis, F. Relativistic GW Calculations on $\mathrm{CH}_{3} \mathrm{NH}_{3} \mathrm{PbI}_{3}$ and $\mathrm{CH}_{3} \mathrm{NH}_{3} \mathrm{SnI}_{3}$ Perovskites for Solar Cell Applications. Sci. Rep. 2014, 4, article no. 4467, DOI: 10.1038/srep04467.

(2) Khadka, D. B.; Shirai, Y.; Yanagida, M.; Miyano, K. Degradation of Encapsulated Perovskite Solar Cells Driven by Deep Trap States and Interfacial Deterioration. J. Mater. Chem. C 2018, 6 (1), 162-170, DOI: 10.1039/C7TC03733C.

(3) Ni, Z.; Bao, C.; Liu, Y.; Jiang, Q.; Wu, W.-Q.; Chen, S.; Dai, X.; Chen, B.; Hartweg, B.; Yu, Z.; Holman, Z.; Huang, J. Resolving Spatial and Energetic Distributions of Trap States in Metal Halide Perovskite Solar Cells. Science 2020, 367 (6484), 1352-1358, DOI: 10.1126/science.aba0893.

(4) Cho, K. T.; Zhang, Y.; Orlandi, S.; Cavazzini, M.; Zimmermann, I.; Lesch, A.; Tabet, N.; Pozzi, G.; Grancini, G.; Nazeeruddin, M. K. Water-Repellent Low-Dimensional Fluorous Perovskite as Interfacial Coating for 20\% Efficient Solar Cells. Nano Lett. 2018, 18 (9), 5467-5474, DOI: 10.1021/acs.nanolett.8b01863.

(5) Jodlowski, A. D.; Roldán-Carmona, C.; Grancini, G.; Salado, M.; Ralaiarisoa, M.; Ahmad, S.; Koch, N.; Camacho, L.; de Miguel, G.; Nazeeruddin, M. K. Large Guanidinium Cation Mixed with Methylammonium in Lead Iodide Perovskites for 19\% Efficient Solar Cells. Nat. Energy 2017, 2 (12), 972-979, DOI: 10.1038/s41560017-0054-3.

(6) Li, X.; Zhang, W.; Wang, Y.-C.; Zhang, W.; Wang, H.-Q.; Fang, J. In-situ Cross-Linking Strategy for Efficient and Operationally Stable Methylammoniun Lead Iodide Solar Cells. Nat. Commun. 2018, 9 (1), article no. 3806 , DOI: $10.1038 / \mathrm{s} 41467-018-06204-2$.

(7) Han, T.-H.; Lee, J.-W.; Choi, C.; Tan, S.; Lee, C.; Zhao, Y.; Dai, Z.; De Marco, N.; Lee, S.-J.; Bae, S.-H.; Yuan, Y.; Lee, H. M.; Huang, Y.; Yang, Y. Perovskite-Polymer Composite Cross-Linker Approach for HighlyStable and Efficient Perovskite Solar Cells. Nat. Commun. 2019, 10 (1), article no. 520, DOI: 10.1038/s41467019-08455-z.

(8) Zhao, Y.; Tan, H.; Yuan, H.; Yang, Z.; Fan, J. Z.; Kim, J.; Voznyy, O.; Gong, X.; Quan, L. N.; Tan, C. S.; Hofkens, J.; Yu, D.; Zhao, Q.; Sargent, E. H. Perovskite Seeding Growth of Formamidinium-Lead-Iodide-Based Perovskites for Efficient and Stable Solar Cells. Nat. Commun. 2018, 9 (1), article no. 1607, DOI: 10.1038/s41467-018-04029-7.

(9) Wang, L.; Zhou, H.; Hu, J.; Huang, B.; Sun, M.; Dong, B.; Zheng, G.; Huang, Y.; Chen, Y.; Li, L.; Xu, Z.; Li, N.; Liu, Z.; Chen, Q.; Sun, L.-D.; Yan, C.-H. A Eu ${ }^{3+}-\mathrm{Eu}^{2+}$ Ion Redox Shuttle Imparts Operational Durability to Pb-I Perovskite Solar Cells. Science 2019, 363 (6424), 265-270, DOI: 10.1126/science.aau5701.

(10) Sadegh, F.; Akin, S.; Moghadam, M.; Mirkhani, V.; Ruiz-Preciado, M. A.; Wang, Z.; Tavakoli, M. M.; Graetzel, M.; Hagfeldt, A.; Tress, W. Highly Efficient, Stable and Hysteresis-Less Planar Perovskite Solar Cell Based on Chemical Bath Treated $\mathrm{Zn}_{2} \mathrm{SnO}_{4}$ Electron Transport Layer. Nano Energy 2020, 75, article no. 105038, DOI: 10.1016/j.nanoen.2020.105038.

(11) Tsai, H.; Asadpour, R.; Blancon, J.-C.; Stoumpos, C. C.; Durand, O.; Strzalka, J. W.; Chen, B.; Verduzco, R.; Ajayan, P. M.; Tretiak, S.; Even, J.; Alam, M. A.; Kanatzidis, M. G.; Nie, W.; Mohite, A. D. Light-Induced Lattice Expansion Leads to High-Efficiency Perovskite Solar Cells. Science 2018, 360 (6384), 67-70, DOI: $10.1126 /$ science.aap 8671 . 